Résumés des conférences et travaux

\title{
Jean-Pierre Callu (1929-2014)
}

\section{Michel Amandry}

\section{OpenEdition \\ Journals}

Édition électronique

URL : https://journals.openedition.org/ashp/1668

DOI : $10.4000 /$ ashp. 1668

ISSN : 1969-6310

Éditeur

Publications de l'École Pratique des Hautes Études

\section{Édition imprimée}

Date de publication : 1 septembre 2015

Pagination : xix-xxi

ISSN : 0766-0677

Référence électronique

Michel Amandry, « Jean-Pierre Callu (1929-2014) », Annuaire de l'École pratique des hautes études (EPHE), Section des sciences historiques et philologiques [En ligne], 146 | 2015, mis en ligne le 28 septembre 2015, consulté le 07 juillet 2021. URL : http://journals.openedition.org/ashp/1668 ; DOI : https://doi.org/10.4000/ashp.1668 


\section{JEAN-PIERRE CALLU \\ $(1929-2014)$}

$\mathrm{J}$

Ean-Pierre Callu est décédé à Donville-les-Bains, dans la Manche, le 29 août.

Né à Paris le 23 octobre 1929, élevé strictement dans un milieu catholique, éloigné de Paris durant l'Occupation, il y reprend ses études dès la Libération. Il entre à l'École normale supérieure en 1951 où il se liera d'amitié à Claude Nicolet (réunis par leur intérêt pour l'histoire romaine et les cours de Jean Bayet et William Seston), obtient l'agrégation de lettres classiques en 1954, et devient membre de l'École française de Rome de 1957 à 1959. À son retour en France se déroulera une carrière universitaire classique, assistant à Strasbourg (1959-1960) et Paris (1960-1963), chargé de cours, maître de conférences puis professeur à Rennes (1963-1972), Paris-X-Nanterre (1972-1988), enfin la Sorbonne (1988-1998). Depuis 1981, il était également chargé d'une direction d'études intitulée « histoire et littérature du Bas-Empire » à l'École pratique des hautes études, IV Section. L'Annuaire. Livret, puis le LivretAnnuaire (!) de l'EPHE consignent de 1981-1982 jusqu'en 1996-1997 le contenu de ses cours mais également, comme c'était alors l'habitude, le nom de ses auditeurs, un public " restreint, mais de qualité » selon ses propres termes. J'en citerai quelquesuns : Paul Jal, Claude Brenot, Sylviane Estiot, Marc Bompaire, Marie-Anne Marié ou François Chausson. Cette direction hybride reflétait parfaitement l'équilibre difficile que conciliait Jean-Pierre Callu, entre histoire monétaire, qu'il n'introduisit dans ses cours qu'en 1985, et histoire culturelle. Latiniste et ayant eu la révélation du BasEmpire, il s'intéressa, contrairement à la volonté de Pierre Courcelle, au « vieux sénateur » Symmaque, s'écartant, selon ses propres termes, de « la partie vivante de la Renaissance théodosienne, cette patristique annonciatrice des siècles chrétiens ». Il va donc traduire et commenter les Lettres (Paris, Les Belles Lettres, 4 vol., 1972-2002) et les Discours (Paris, Les Belles Lettres, 2009) de ce « représentant typique d'une classe encore puissante et consciente de l'être, conservatrice, paternaliste... mais qui constituait un rouage de première importance dans le système politique de l'Empire tardif » (L. Cracco Ruggieri). Jean-Pierre Callu donna également, avec Anne Gaden et Olivier Desbordes, le premier tome de l'Histoire Auguste (Paris, les Belles Lettres, 1992) ainsi que la Correspondance de Gerbert d'Aurillac, pape de l'an mil sous le nom de Sylvestre II, avec Pierre Riché (Paris, les Belles Lettres, 1993).

Mais, dès 1954, l'enseignement de Jean Lafaurie à l'École pratique l'attira. Il était donc « assis, entre deux chaises, sur le strapontin de la numismatique, une simple science auxiliaire pour les philologues et les historiens ». Son Genio Populi Romani (295-316) : contribution à une histoire numismatique de la Tétrarchie paru chez Champion en 1960, était très novateur. La publication de sa thèse de doctorat, La politique monétaire des empereurs romains de 238 à 311 (BEFAR 214, De Boccard, 1969) fut un événement, et reste un livre essentiel. Dans ce monument exceptionnel d'érudition, l'historien montrait « l'importance du $\mathrm{III}^{\mathrm{e}}$ siècle comme phase de transition et de maturation des transformations du IV ${ }^{\mathrm{e}}$ siècle » (L. Cracco Ruggieri), s'intéressant au 
monnayage de bronze en Orient de 238 à 276 et tentant de dégager des indications sur le volume des émissions, la circulation des espèces, les systèmes métrologiques pour démontrer « combien était alors facile la conversion entre les séries locales de bronze et les multiples impériaux d'argent » (L. Cracco Ruggieri).

Jean-Pierre Callu aimait fréquenter le Cabinet des médailles, « éprouvant le sentiment délicieux d'y faire une visite », où les heures passaient vite avec « les dénombrements, les tabulations, les statistiques » et où les idées pouvaient s'épanouir grâce à la majesté des lieux. Mais, s'il avait pénétré les arcanes de la numismatique, il n'en était pas devenu numismate pour autant. Ce serait lui faire injure que de le ranger au nombre de ces spécialistes, scrutateurs de petits disques de métal, l'œil vissé à leur loupe ou au microscopique : les typologues de Cabinet lui inspiraient de la méfiance. Pour Jean-Pierre Callu, la pièce individuelle, observable et palpable, ne parle pas ou, si elle le fait, on aurait tort de trop s'y fier. Il faut accumuler des individus qui finissent par s'intégrer dans d'évidents regroupements, additionner du morcelé non significatif pour faire transparaître un sens, récolter méthodiquement des exemplaires reclassés en séries, mettre ainsi au jour des tendances générales, des directions lisibles, construire « le fait monétaire », sur lequel s'échafaude la preuve patente ou logique. De la Politique monétaire à l'Or monnayé II paru en 1990 (Cahiers Ernest-Babelon 3), en collaboration avec Xavier Loriot, la démarche intellectuelle n'a pas varié. Il s'est toujours agi d'étudier la vie de la monnaie une fois qu'elle a quitté l'officine, de rétablir sa dynamique, de lire son histoire là où les textes se taisent. Jean-Pierre Callu avait très rapidement saisi que la numismatique ne devait pas s'enfermer sur elle-même, mais s'ouvrir à des voies nouvelles. Si les tentatives d'évaluation des volumes de production, ce qu'il appelait la métanumismatique, ont rencontré en lui une certaine méfiance, l'approche statistique ne l'a en revanche pas rebuté. Il a également perçu très tôt, dès la fin des années 1960, avec Jean-Noël Barrandon, Claude Brenot, Cécile Morrisson et d'autres, au sein du centre Ernest-Babelon à Orléans, l'intérêt extraordinaire des méthodes d'analyse nucléaire appliquées dans le domaine de la numismatique

L'Institut ajouta la dernière touche à son cursus exemplaire. Il fut élu à l'Académie des inscriptions et belles-lettres le 10 février 1995 au siège de Pierre Marot. MarieAnne Marié et moi-même organisèrent la cérémonie de remise de son épée. Celle-ci eut lieu le 21 octobre 1996, non pas dans les grands salons du rectorat, mais à l'Hôtel de la Monnaie. Ce choix était le sien témoignant ainsi que « sa vocation ne le portait ni vers les amphithéâtres ni vers l'enseignement au microphone ». Des Journées internationales d'histoire monétaire autour de son œuvre furent organisées en octobre 2000 et les communications publiées dans la Revue Numismatique 2003.

Ses écrits sont commodément rassemblés dans deux volumes : Culture profane et critique des sources de l'Antiquité tardive : trente et une études de 1974 à 2003, Collection de l'École française de Rome 361 (Paris, 2006) et La monnaie dans l'Antiquité tardive. Trente-quatre études de 1972 à 2002 (Edipuglia, Bari, 2010).

Jean-Pierre Callu se définissait comme un chercheur isolé, un « amateur de bonne volonté ». Son contact pouvait intimider, tant sa culture et son savoir étaient immenses. Mais sa « courtoisie, même distanciée, n'était pas trop décourageante » (C. Nicolet). Il ne fuyait pas les honneurs, mais ne les recherchait pas non plus. À la Société française de numismatique, où il était entré en 1960 et dont il était membre honoraire depuis 
2002, il avait décliné la proposition qui lui avait été faite d'en devenir le président, se contenant d'en être le vice-président entre 1981 et 1984. Mais il fut le président de la Société nationale des antiquaires de France en 1992. Il s'était pris d'affection pour cette vieille société et il était fidèle à ces rendez-vous du mercredi qui l'ont fait pressentir ce que seraient ceux du vendredi.

Retenons l'enseignement fondamental de ses écrits, dont il disait modestement qu'il subsistait dans certains « des éléments à ne pas irrémédiablement écarter du débat », son invitation à faire preuve d'imagination et à toujours chercher des voies novatrices. Son dernier écrit, dont il n'a pas vu la parution dans la Revue Numismatique 2014, p. 21-29, qui rendait hommage à l'œuvre monumentale de P. Bastien, revient sur cette incompréhension supposée, mais pas tout à fait erronée, entre numismates et historiens. Jusqu'au bout, Jean-Pierre Callu aura souhaité une exploitation du matériel numismatique selon des interrogations complémentaires de celles propres à la numismatique.

Michel AmANDRY

N.B. : Les citations de ce texte sont extraites de la plaquette L'épée de Monsieur Jean-Pierre Callu, Hôtel de la Monnaie, 21.X.1996 (Cahors, France Quercy, 1997). 